\title{
Distribution Generation Cost-Benefit Model and Simulation Based on System Dynamics Take Photovoltaic Power Generation as an Example
}

\author{
Jiang Qing-guo ${ }^{1}$, Zhang Li-zi ${ }^{2}$ and Wang Yun-yun ${ }^{3}$ \\ School of Electrical \& Electronic Engineering, North China Electric Power \\ University, Beijing 102206, China \\ ${ }^{1}$ lyou2004@163.com, 2lizizhang@sina.com, ${ }^{3}$ ncepuwangyun@163.com
}

\begin{abstract}
Economic benefit analysis of distributed generation $(D G)$ is helpful for the formulation and adjustment of the DG industry policy, and the dynamic visual simulation model couldimprove the accuracy in decision making. This paper first reviewed the domestic and foreign research status of distributed generation(DG) economic benefit, then analysed the direct benefits, indirect benefits and the costs of DG through the cost-benefit master model of DG set up by System Dynamics method. Meanwhile, each cost-benefit sub model is also provided. Finally simulation for $5 \mathrm{MW}$ photovoltaic power station is carried out and its costs and benefits are presented. The validity of the model was verified for the results conforming to the anticipated target, the results also showed that subsidies had significant effects on the benefits of $D G$ and the indirect benefits, especially carbon reduction benefit are obvious.
\end{abstract}

Keywords: distributed generation; cost; benefit; system dynamics; simulation

\section{Introduction}

DG industry requires economic benefit analysis to set and adjust the related policies. At present, the primary focuses of economic benefit analysis are thedirect cost efficiency and environmental benefit. GULL studied the cost efficiency and economic benefit of the small-scale distributed power and centralized power [1]; Bakos established and verified an economic evaluation model for the user-side wind-solar co-generation system [2]; Flores analyzed six major factors which affected the distributed power generation operation and cost[3]; Moradi established an autonomous model for distributed power grid and evaluated its economical efficiency and reliability [4]; Amor made an economic assessment for distributed renewable energy generation system [5].

Researches in China for DG focues on the economical access to system, the environmental benefit, the technological economy, the economic dispatch and the emission reduction benefit.

Currently, most researches focus on the static evaluation, which does not fully present the dynamic interactions among the indexes. A growing body of literature suggests that a number of indexes are used to evaluate the economic efficiency of DG and there are some obvious direct and indirect correlations among them. For example, the increase of distributed capacity can directly lead to the decrease in power plants capacity, especially thermal plants. It can also indirectly save the investment of transmission and distribution and improve environmental benefit. Therefore, all direct and indirect relationships should be adequately embodied in the discussion.

This paper introduces system dynamics (SD) method which is applied for the costprofit of DG based on rhe existing research. On the one hand, the cost-benefit evaluation model is set up from the system perspective to express the main indexes and quantized 
relations between the indexes of DG dynamically and visually. On the other hand, considering the photovoltaic (PV) industry in China has been relatively mature and relevant data will be credible, we will take PV generation as an example and emphasize the indirect benefit evaluation of DG.

This paper is organized into five sections. In the section 1, we introduce the research status of cost-profit of DG. Section 2 introduces the development status of DG in China. Section 3 establishes the cost-benefit SD model of DG through the software called Vensim PLE (Version 5). Section 4 validates the model through simulation based on the data of a 5-MW PV plant. Section 5 discusses the effect of generation subsidies and the indirect benefit on the development of DG.

\section{The Development of DG in China}

Distributed generation is described as a kind of power generation facility for balancing the energy of distribution network or a kind of multi-generation facility for comprehensive energy-step-utilization. It is usually installed near to users, which makes it possible to reach to self-sufficiency and export the surplus in user side to the electricity grid.

There are two major characteristics of DG compared with the traditional centralized generation.

DG can transmit energy closely to the corresponding load through distribution network without the need of large-scale grid and long-distance high-voltage transmission. As a result, the loss of line, the capital cost and operational cost will be significantly reduced.

With the multi-functions of power generation, heating, cooling, hot water supplying and other energy services, distributed generation can effectively achieve cascaded and comprehensive energy utilization. In addition, it can also improve the security, efficiency and reliability of energy supply.

\subsection{DG and Related Laws}

The Guidance on Developing DG of Natural Gas, which was the first legal document aiming at distributed generation, was issued in August, 2011 by National Development and the Ministry of Finance, the Urban and Rural Housing Ministry and National Energy Commission. The document states that during the twentieth Five-year, about 1,000 DG projects of natural gas will be launched and about $10 \mathrm{DG}$ energy demonstration areas with typical characteristics will be built. In the next five to ten years, there will be a great breakthrough in the development of DG. The industrial system of DG will be formed with the independent intellectual property. More professional companies will pay more attention to the construction, operation and management to find out a suitable business mode for DG of the natural gas.

National Energy Commission issued the Twelfth Five-year Plan of Renewable Energy Sources on August 6th, 2012. The plan points out that the total installed capacity will reach to 290 million MW for hydropower and 100 million MW for grid-connected wind turbines by the end of the twelfth Five-year (2015). Solar collector area will reach to 45 million square meters and the total utilization amount of biomass energy such as methane, garbage and straw will reach to 50 million tons of standard coal.

The National Development and Reform Commission issued Interim Procedures of Distributed Generation Management on July 18th, 2013, concerning the issues of DG's construction management and operation management,,etc.. This government document will accelerate the large-scale development of DG in China and improve its practical operation. 


\subsection{Cost-Benefit Level of DG}

DG in China is still in the pilot stage. According to the investigation from the National Energy Administration, DG is suitable for the following fields:

a. Small hydropower with generation-supply-consumption integration;

b. Demand-side PV generation combined with surrounding buildings;

c. Distributed wind power and PV grid-connected system;

d. Small-size wind-solar-battery supplementary electricity generation;

e. Industrial by-product heat and pressure and multi-generation technologies;

f. Gasification, direct-fired, biogas generation and multi-generation technology of farming and forestry surplus, livestock wastes, organic waste-water and household refuse;

g. Geothermal energy generation, ocean power generation and multi-generation technology;

h. Multi-generation of natural gas, coal-bed methane power generation.

PV generation is the main DG in China. Table 1 provides brief description of cost parameters of DG.

Table 1. Cost of DG Generation in China

\begin{tabular}{cccc}
\hline Type of unit & $\begin{array}{c}\text { Installed capacity } \\
(\mathrm{kW})\end{array}$ & $\begin{array}{c}\text { Cost of investment } \\
(\text { 元 } / \mathrm{kWh})\end{array}$ & $\begin{array}{c}\text { Energy } \\
\operatorname{cost}(\mathrm{yuan} /(\mathrm{kWh}))\end{array}$ \\
\hline Micro gas turbine & $25-75$ & $8000-12000$ & $0.44-0.8$ \\
unit & $5-2000$ & $24000-32000$ & $0.6-0.8$ \\
Fuel cell & $20-2000$ & $8000-12000$ & $0.8-1.2$ \\
Wind turbine & $1-100$ & $12000-52000$ & $1.2-1.6$ \\
Photovoltaic plant & & \\
\hline
\end{tabular}

At present, distributed generation has no advantages on investment compared with the thermal power plants, but it highlights the environment profit. The average generation cost of the thermal power plant now in China is $0.36 ¥ / \mathrm{kWh}$, or more than $1.3 ¥ / \mathrm{kWh}$ when the environmental cost added. So, if the environmental profit concerned, the total revenue of DG will be considerable, which is also including government subsidies for generation. Detail analysis is as follow.

\section{Cost-Benefit Analysis of DG}

DG refers to the power generation method for generating electricity directly in load area or near the load center, the benefits include a variety of direct and indirect economic benefits, while the costs include fixed cost like fixed asset investment (equipment, etc.) and variable cost, such as energy, personnel wages, etc.

\subsection{Benefit Analysis of DG}

Reduction of line loss, electricity price, investment in power generation capacity, improvement of the economic benefit of environment and delay of transmission upgrades are five aspects of the economic benefits of DG, and it's difficult to analyze the reduction of investment in generation capacity and delay transmission upgrade benefits quantitatively [6]. In the above five aspects of economic benefits of DG, reduction of line loss, improvement of the economic benefits of the environment and reduction of investment in power generation capacity can obviously promote the economic benefits; reduction of tariff benefits and delay of transmission upgrade transformation benefit are also feasible in theory. But effect on user's price by DG depends on many uncertain factors, such as the size of the installed capacity, power generation costs, demand elasticity 
and wholesale price,etc., so quantitative analysis of the effect on user's price will not carried out in this paper.

In order to promote the development of DG, the state provides distributed power generation with certain subsidies recently. On August 2013, Interim Measures for the Management of Distributed Generation was issued by the National Development and Reform Commission requires subsidies for DG construction or generated energy to DG enterprises, which met relevant standards", and Notice on Promoting the Healthy Development of Photovoltaic Industry by the Use of Price Leverage defines that the amount of subsidies for photovoltaic electricity price is $0.42 \mathrm{Yuan} / \mathrm{kwh}$, and power generation subsidies have become an important source of DG revenue. Thus, reduction of line loss, improvement of the economic benefits of the environment, reduction of investment in power generation capacity, the investment in the grid construction and the subsidies from government are considered to be the main parts of benefits in this paper.

\subsection{Cost Analysis of DG}

The cost of DG mainly includes the fixed cost like the power generation equipment, and variable cost, such as personnel wages, operating management costs, etc. On the one hand, this paper mainly focus on the effect of benefit and indirect benefit of DG. On the other hand, the differences of unit capacity fixed cost and variable cost caused by the same type with different DG units, installed capacity, geographical location are not obvious in the long period. In order to facilitate data processing, in this paper, the fixed cost of DG is equivalent to the investment of the installed capacity, and the variable cost is the operating cost.

\section{DG Input-Output System Dynamics Model}

System Dynamics (SD) method firstly was applied by professor J. W. Forrester of MIT in 1950s, and has been widely applied in the fields of energy, society and economy[11]. By analyzing the feedback loop structure, establishing the system dynamic model, changing the state value of the relevant variables, and understanding the different behavior patterns under different strategies, SD method can complete the optimization of the strategy, and it has the function of policy analysis and decision-making, and SD method has been widely used in the electric power industry. In this chapter, we first define the objectives of the model, and then construct the DG cost-benefit dynamics model, and give the relationship between the main factors.

\subsection{System Target}

From the view of cost and benefit, the target of the cost-benefit system of DG are as follows: (1) The annual costs and benefits of the distributed generation enterprises are basically balanced without consideration of the indirect benefits. (2) With considering the indirect benefits, the cumulative net profits of the distributed generation enterprises should increase year by year, or tend to be upward in the operation cycle. Based on the two targets above, this paper then analyze the dynamic influence of DG subsidies and the carbon trading price changes to DG cost-benefit model.

\subsection{Main System Model of DG}

According to the analysis of DG cost-benefit model in Chapter 2, combining system targets, the main indicators of DG cost-benefit model are as in Table 2.

Besides, in order to analyze the system targets (1) and (2), actual profit and loss index of DG enterprises are added to the DG cost-benefit model; The actual profits and loss indexes (without subsidies) of the DG enterprises are added to the model so as to analyze the influence of generation subsidies to the annual benefits of the DG enterprises, as 
shown in Figure 1. Considering that the DG fixed investment is a one-time investment, simulation period $\mathrm{n}$ is added to the model to average fixed investment to each simulation cycle. The selection of the simulation period is based on the life cycle of DG fixed assets.

Table 2. Main Indicators of DG Cost-Benefit Model

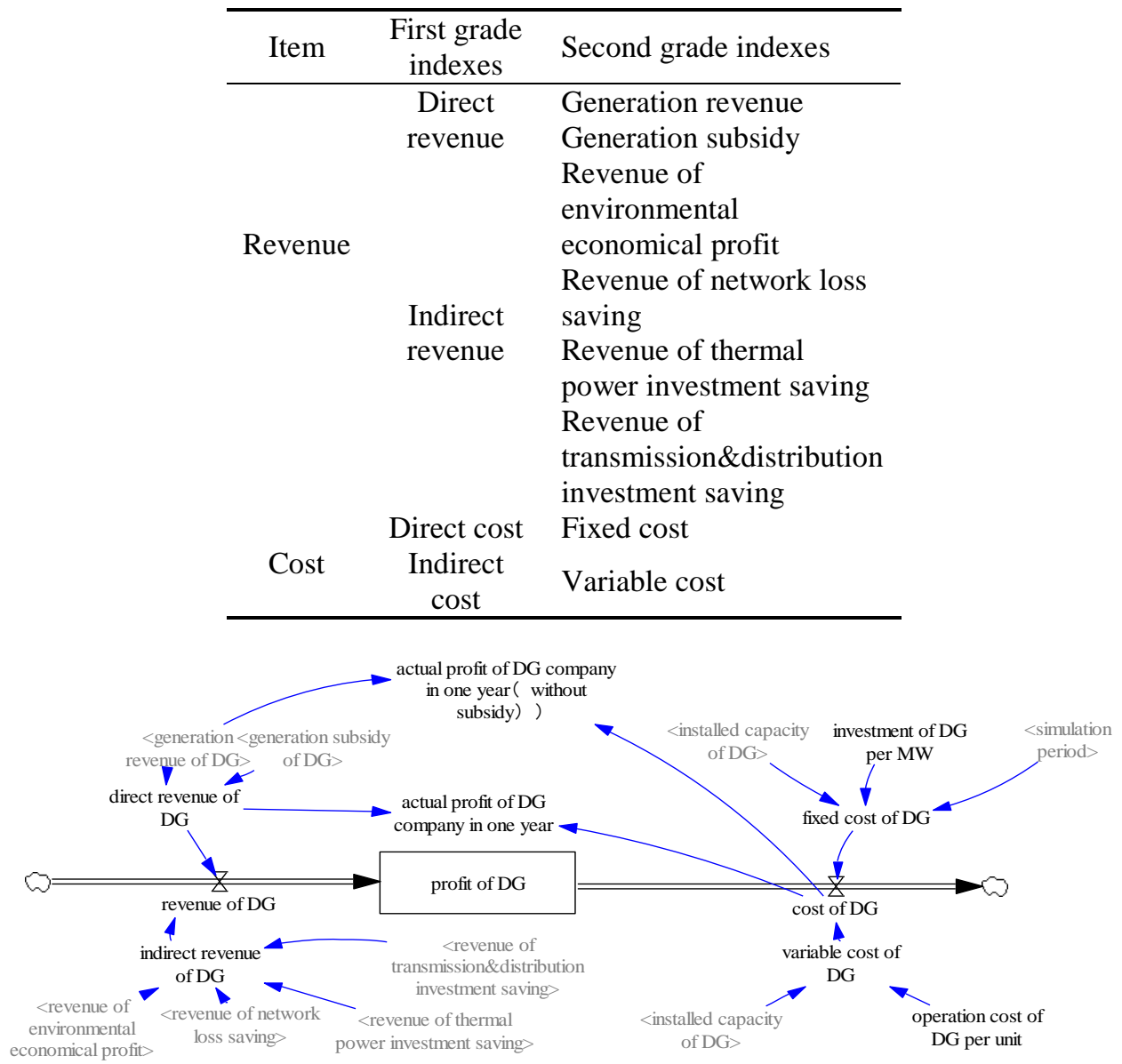

Figure 1. DG Cost-benefit System Dynamics Master Model

\subsection{Sub-System Model}

The main DG cost-benefit model is composed of two modules: cost and benefit. Figure 1shows the main cost-benefit model, then each model of the benefit model are analyzed below and the relationship of some main elements are explained.

(1) Generation benefit model of DG

The benefits of generating electricity depend on distributed generation utilization hours, capacity of distributed generation and online electricity price. The total benefits of distributed generation are the accumulation value of the annual generating electricity benefits, as shows in Figure 2.

The main equations include:

$B g=\sum_{i=1}^{n} B g_{i}$

Where $B g$ stands for the total benefits of distributed generation; $B g_{i}$ stands for the annual generating electricity benefits; $n$ is the simulation period and $i$ is one certain year;

Assume that the generating electricity benefit is 0 when the simulation starts; 
$Q_{d i}=h_{d i} \times C_{d i}$

Where $Q_{d i}$ is the generation of electricity of the year; $h_{d}$ stands for the distributed generation utilization hours; $C_{d}$ is the capacity of distributed generation;

$B g_{i}=Q_{d i} \times p_{i}$

Where $p_{i}$ is the feed-in tariff of one certain year.

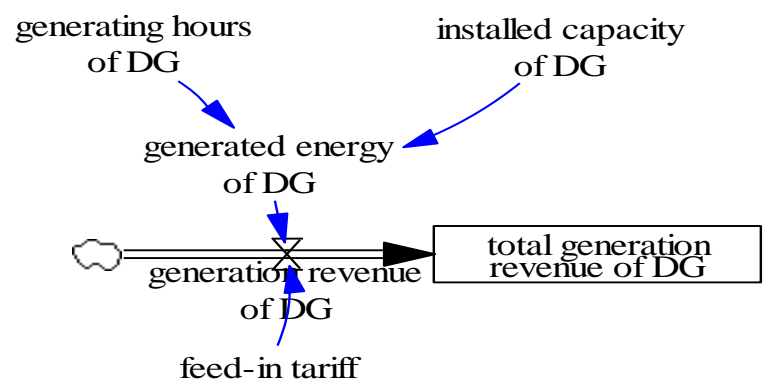

Figure 2. Generation Benefit Model of DG

(2) Generation subsidy model of DG

Generation subsidy depends on the generation of electricity and subsidy coefficient (namely subsidy price), and the total subsidies of distributed generation are the accumulation value of the annual power generation subsidies, as shown in Figure 3.

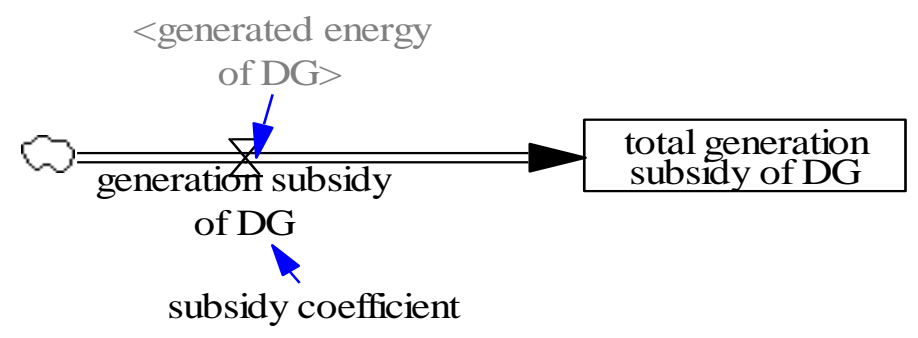

Figure 3. Subsidy Model of DG

The main equations include:

$S g=\sum_{i=1}^{n} S g_{i}$

Where $S g$ stands for the total power generation subsidies; $S g_{i}$ is the power generation subsidy of one year.

Assume that the power generation subsidy is 0 when the simulation starts;

$S g_{i}=Q_{d i} \times \eta_{s i}$

Where $\eta_{s i}$ is the subsidy coefficient.

(3) Revenue of thermal power investment saving model of DG

Thermal power investment saving is capacity investment saving of thermal plants in the long run.The equivalent installed capacity to thermal power is calculated based on the generating hours of DG,installed capacity of DG and generating hours of thermal power, as shown in Figure 4.

The main equations include: 
$I g=\sum_{i=1}^{n} \operatorname{Ig}$

Where $I g$ stands for the total reduced power generation capacity investment; $I g_{i}$ stands for the reduced power generation capacity investment of the year.

Assume that the reduced power generation capacity investment is 0 when the simulation starts;

$C_{f d i}=\frac{Q_{d i}}{h_{t i}}$

Where $C_{f d i}$ is the equivalent thermal power installed capacity, $h_{t i}$ stands for thermal power generation utilization hours;

$I g_{i}=\frac{C_{f d i} \times I_{t p c i}}{n}$

Where $I_{t p c i}$ is the thermal power unit capacity investment;

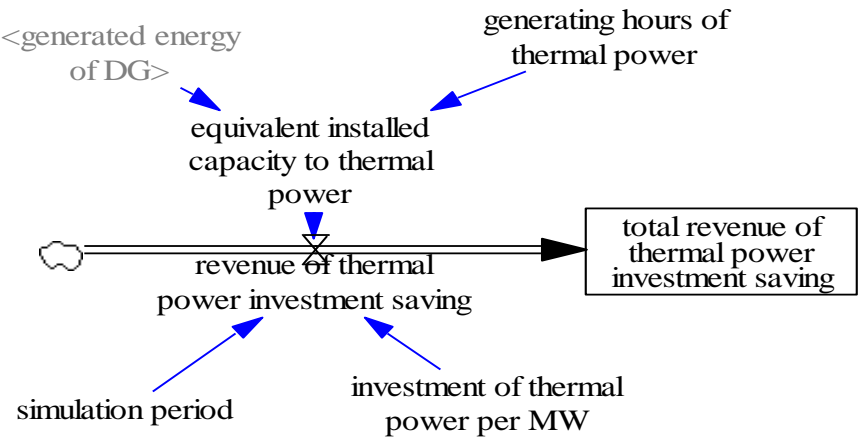

Figure 4. Generation Capacity Investment Saving Model of DG

(4) Revenue of transmission\&distribution investment saving model of DG

Reducing power grid construction investment benefit refers to the indirect benefit gained by reducing power demand of the load on the long distance transmission due to the access of distributed generation, thereby reducing the investment on the newly installed capacity of transmission lines in the future and reducing the investment of grid construction. In this case, we consider the reduction of equivalent thermal power installed capacity is equivalent to reduction of the transmission capacity, as shown in Figure 5.

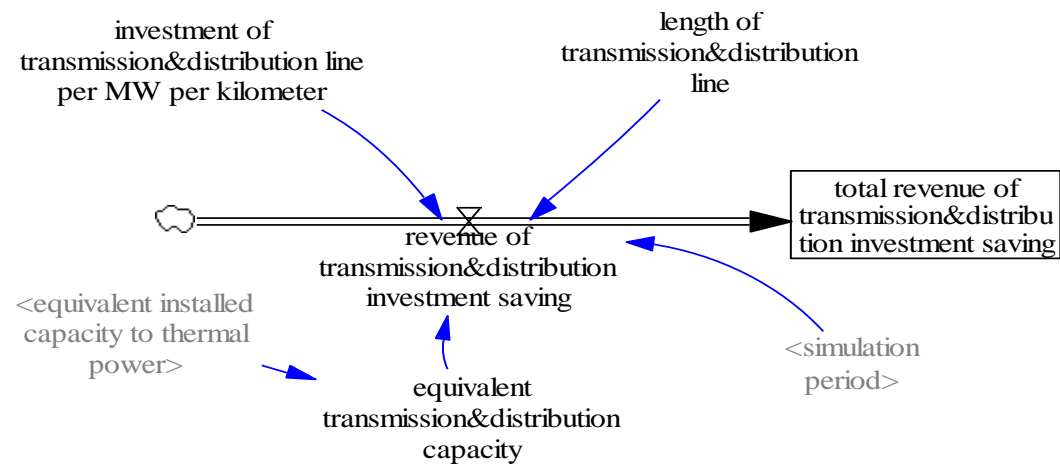

Figure 5. Transmission Capacity Investment Saving Model of DG 
The main equations include:

$I S=\sum_{i=1}^{n} I s_{i}$

Where $I s$ stands for the reduction of the grid reduced total investment, $I s_{i}$ stands for the reduction of grid reduced investment every year;

Suppose that the total investment of power grid construction is 0 when the simulation starts;

$C_{t i}=C_{f d i}$

Where $C_{t i}$ stands for the equivalent transmission capacity;

$I s_{i}=\frac{I_{t c i} \times C_{t i} \times l_{i}}{n}$

Where $I_{t c i}$ stands for the grid investment per kilometer per capacity; $l_{i}$ stands for the length of transmission line;

(5) Revenue of network loss saving

The access of distributed generation will reduce transmission line loss and the distribution line loss [12].The line loss reduction benefit depends on equivalent thermal power installed capacity, thermal power utilization hours, the loss rate of transmission and distribution line and online electricity price, and the total line loss reduction benefits are the accumulation value of the annual line loss reduction benefit, as shown in Figure 6.

The main equations include:

$B l=\sum_{i=1}^{n} B l_{i}$

Where $B l$ stands for the total benefit obtained from the line loss reduction; $B l_{i}$ stands for annual benefit obtained from line loss reduction

Suppose that the total investment of power grid construction is 0 when the simulation starts;

$l_{i}=C_{f d i} \times h_{t i} \times\left(\eta_{t}+\eta_{d}\right)$

Where $l_{i}$ stands for line loss; $\eta_{t}$ stands for the transmission line loss rate; $\eta_{d}$ stands for the distribution line loss rate;

$B l_{i}=l_{i} \times p_{i}$

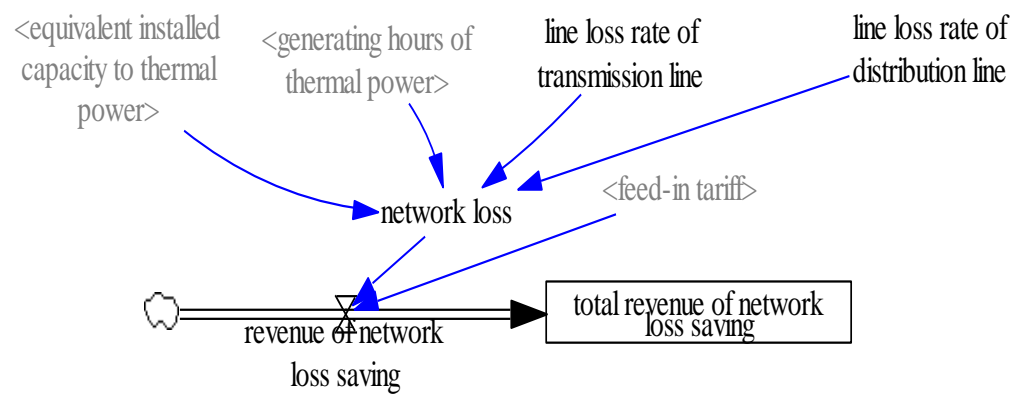

Figure 6. Benefit Model of Loss Reduction 
(6) Revenue of environmental economical profit

The environmental benefit of distributed power mainly reflects in the aspect of emission reduction. Clean renewable energy resources of DG will lead significant emission reduction of $\mathrm{CO} 2$. The environment economic benefits of $\mathrm{DG}$ is evaluated based on the PV generation and transaction price of $\mathrm{CO}_{2}$.

The main equations include:

$B e=\sum_{i=1}^{n} B e_{i}$

Where $B e$ stands for total economic benefits of environment; $B e_{i}$ for the annual economic benefits of environment;

Suppose that the total economic benefits of environment is 0 when the simulation starts;

$Q_{\mathrm{CO}_{2} i}=\eta_{\mathrm{CO}_{2} i} \times Q_{d i} \times q_{b m}$

Where $Q_{\mathrm{CO}_{2} i}$ stands for $\mathrm{CO}_{2}$ emissions; $\eta_{\mathrm{CO}_{2} \mathrm{i}}$ for $\mathrm{CO}_{2}$ emission factor; $q_{b m}$ for generation standard coal consumption rate;

$B e_{i}=Q_{\mathrm{CO}_{2} i} \times p_{\mathrm{CO}_{2} i}$

Where $p_{\mathrm{CO}_{2} i}$ stands for $\mathrm{CO}_{2}$ trading price.

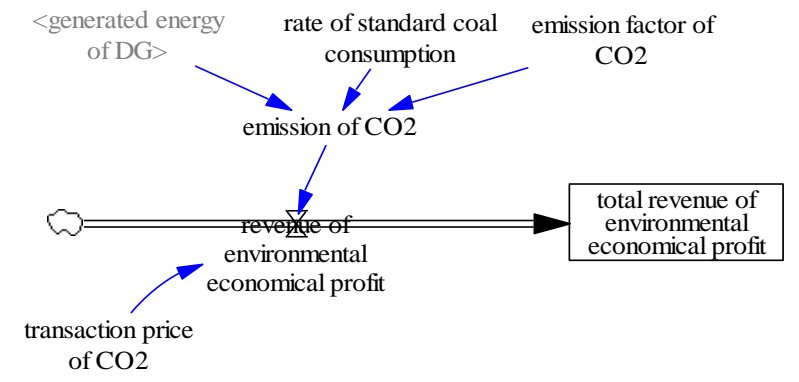

Figure 7. Environmental Benefit Model of DG

\section{The Initial Simulation and Analysis of the Model}

\subsection{Model Assumption and Parameters Description}

As shown in Figure 8, assume that the total installed capacity of thermal power is $60 \mathrm{MW}$ in supply side, the total load is 50MW, the voltage level of transmission grid is $110 \mathrm{kV}$, and the voltage level of distribution network is $10 \mathrm{kV}$.

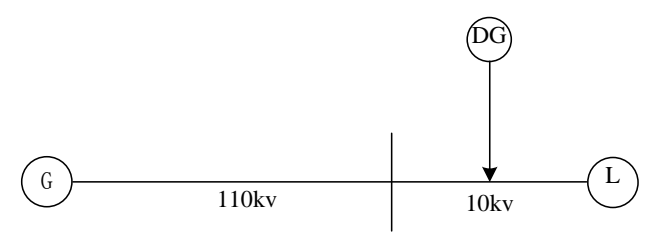

Figure 8. Simplified Network Model 
In order to meet the requirements of load growth, there are 5MW distributed PV added in the distribution network. In the transmission level, the effect of the distributed power access to transmission grid to the loss rate in transmission is ignored because that the voltage level of transmission grid is high, the line loss rate is low, and the distributed power capacity is relatively small relative to transmission grid capacity. And the line loss rate of transmission grid is regarded as $2 \%$; in the distribution level, the line loss effect of distributed power access to distribution network is a complex problem, which depends on the distribution network structure, the ratio and the access locations of distributed power capacity access to the grid relative to the load and so on. Reference 12 shows that, in $10 \mathrm{kV}$ chain distribution network, when the distributed power is in the best access locations, and the ratio of distributed power and load capacity is $10 \%$, the line loss in distribution network is about $10 \%$. Suppose that the line loss rate is $7 \%$ in distribution network before new distributed power is added, and then the line loss rate is $6.3 \%$ after new distributed power is added. The number of DG cost - income dynamics model input parameters is 15 , every parameter's value and description is shown in Table 3.

Table 3. Model Parameters and Instructions

\begin{tabular}{|c|c|c|}
\hline Parameter & Value & Instruction \\
\hline $\begin{array}{l}\text { generating hours of DG } \\
\text { (h/a) }\end{array}$ & $\begin{array}{l}1000- \\
1500\end{array}$ & $\begin{array}{l}\text { Normal generating hours of } \\
\text { DG, take the mean value } \\
1200 \text { as theparameter }\end{array}$ \\
\hline $\begin{array}{l}\text { Installed capacity of DG } \\
\quad(\mathrm{MW})\end{array}$ & 5 & Moderate scale of DG \\
\hline $\begin{array}{l}\text { Feed-in tariff } \\
\text { (yuan/MWh) }\end{array}$ & 415 & $\begin{array}{l}\text { average feed-in tariff of } \\
\text { China in } 2014\end{array}$ \\
\hline $\begin{array}{l}\text { Subsidy coefficient } \\
\text { (yuan/MWh) }\end{array}$ & 420 & $\begin{array}{l}\text { 《the notification about } \\
\text { promoting healthy } \\
\text { development of } \\
\text { photovoltaic industry by } \\
\text { usingprice leverage》 }\end{array}$ \\
\hline $\begin{array}{l}\text { generating hours of } \\
\text { thermal power }(\mathrm{h} / \mathrm{a})\end{array}$ & 5000 & $\begin{array}{l}\text { normal generating hours of } \\
\text { thermal power }\end{array}$ \\
\hline $\begin{array}{l}\text { Investment of thermal } \\
\text { power per MW ( } \\
\text { yuan/MW })\end{array}$ & 3500 & $\begin{array}{l}\text { average investment of } \\
\text { thermal power per MW of } \\
\text { China in } 2014\end{array}$ \\
\hline Simulation period (a) & 20 & $\begin{array}{l}\text { average life of Crystalline } \\
\text { silicon photovoltaic battery }\end{array}$ \\
\hline $\begin{array}{l}\text { Line lossrate of } \\
\text { transmission line }(\%)\end{array}$ & $\begin{array}{l}2 \\
6.3\end{array}$ & \\
\hline $\begin{array}{l}\text { Line lossrate of } \\
\text { distribution line }(\%) \\
\text { Length of } \\
\text { transmission\&distribution }\end{array}$ & $\begin{array}{l}100 \\
0.8\end{array}$ & $\begin{array}{l}\text { 《Quantities and the } \\
\text { engineering cost list of } \\
110 \mathrm{kV} \text { line typical scheme }\end{array}$ \\
\hline line $(\mathrm{km})$ & & of SGCC 》, Scheme1I-H \\
\hline $\begin{array}{l}\text { Investment of } \\
\text { transmission \&distribution }\end{array}$ & & $\begin{array}{l}; \quad \text { 《List of overhead line } \\
\text { transmission capacity》 }\end{array}$ \\
\hline line per $\mathrm{MW} \cdot \mathrm{km}$ & & \\
\hline $\begin{array}{l}10,000 \text { yuan } / \mathrm{km}-\mathrm{MW}) \\
\text { rate of standard coal } \\
\text { consumption }(\mathrm{g} / \mathrm{kWh})\end{array}$ & 330 & $\begin{array}{l}\text { average coal consumption } \\
\text { rate of } 600 \mathrm{MW} \text { unit }\end{array}$ \\
\hline Emission factor of $\mathrm{CO}_{2}$ & 2.66 & international general value \\
\hline $\begin{array}{l}\text { Transaction price of } \mathrm{CO}_{2} \\
\text { (yuan/ton) }\end{array}$ & $15-100$ & $\begin{array}{l}\text { Value of Shenzhen Carbon } \\
\text { Exchange in } 2014\end{array}$ \\
\hline Operation cost of DG per & 16 & average operation cost of \\
\hline
\end{tabular}




\begin{tabular}{|c|c|c|}
\hline $\begin{array}{l}\text { MW }(10,000 \\
\text { yuan/MW })\end{array}$ & & $10 \mathrm{MW}$ pv station \\
\hline $\begin{array}{l}\text { Investment of DG per } \\
\text { MW }(10,000 \\
\text { yuan/MW })\end{array}$ & 1300 & $\begin{array}{l}\text { crystalline silico : } \\
10 y u a n / W, \text { the additional } \\
\text { fee equals } 30 \% \text { of } \\
\text { crystalline silicofee, } \\
\text { including access fee, } \\
\text { transformer cost,etc. }\end{array}$ \\
\hline
\end{tabular}

\subsection{The Initial Simulation Result}

Through simulation, the simulation results of objective (1) and objective (2) in 2.1 system goal is shown in Figure 9. Based on the currently price and subsidy policy, PV distributed power’s earnings is positive, and annual profit is about $¥ 192,000 / \mathrm{MW}$. Besides that, accumulated profit increases year by year, which meets the target.

According to the current subsidy standards, if 5MW distributed PV power plant generating power achieves subsidies totally, the plant will receive an annual subsidy of about $¥ 510,000 / \mathrm{MW}$, that is, if there is no government support, distributed power generation plant would loss $¥ 318,000 / \mathrm{MW}$ every year. So, as shown in Figure 10, distributed PV power plant highly depends on government support.

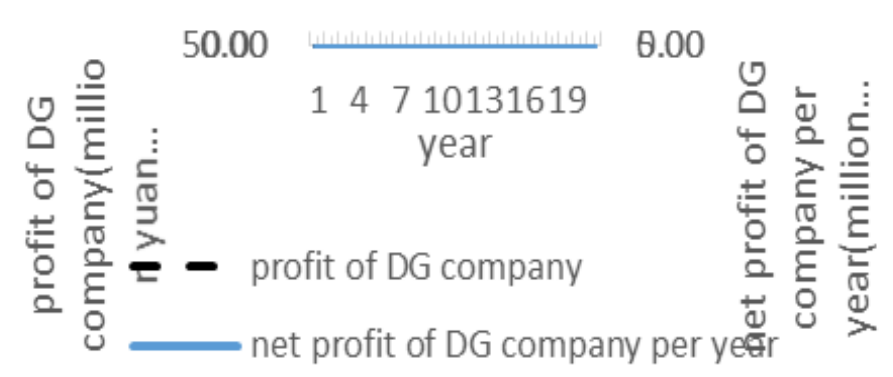

Figure 9. Simulation Results of Objective (1) and Objective (2)

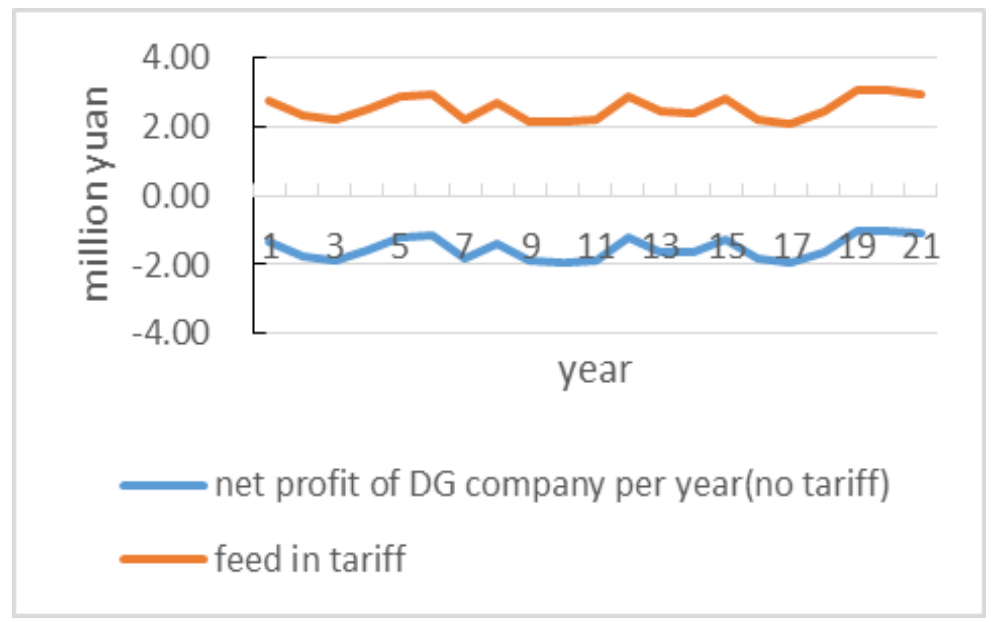

Figure 10. Annual Subsidies Benefit of DG

DG indirect benefits are significant, and the average annual income is about $¥ 150,000 / \mathrm{MW}$, of which environmental benefits are the most obvious, followed by the benefits of the line loss reduction and generation capacity investment reduction, and 
finally is the benefits of power grid construction investment reduction, as shown in Figure 11.

Finally, from the perspective of state support for the photovoltaic industry, comparing Figure 10 and Figure 11, approximately $30 \%$ of the subsidies which the state gives to solar DG every year is recovered through indirect benefits, and 70\% supports the development of solar industry. In the recent years, affected by the pace of international economic development slowdown, carbon trading price has been at a low level. If the carbon trading price rises in the future, and DG carbon emission reductions could be included in carbon trading range, DG indirect benefits would further increase.

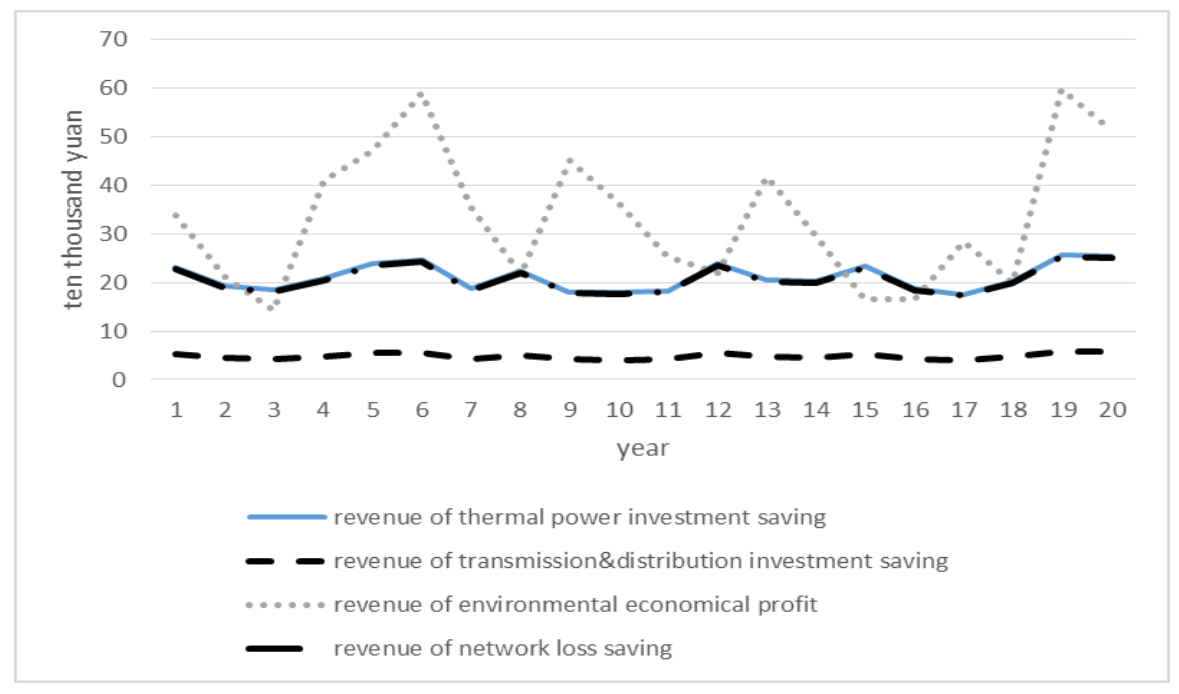

Figure 11. Annual Indirect Benefit of DG

\section{Conclusion}

System dynamic methods are used in this paper, and DG cost-benefit model is established. Then, the system running process is simulated as 5MW distributed PV generating an example, and the simulation result meets the target, which verifies the model. The model can also further analyzes the impact of changes which lies in policy, economic and environmental on DG cost-benefit via adjusting various parameters, such as the amount of subsidies, carbon prices.

The study shows that: (1) The government subsidies play an essential role in the DG development. It should be supported during a short time in order to ensure the healthy and stable development of distributed power generation and some other related industries. (2) The indirect benefits of DG are obvious, especially the reduction indirect benefits. Currently, DG carbon reductions have not been included in the scope of carbon trading and the price given here is based on Shenzhen Carbon Stock Exchange price which remains at a low level. Consequently, there is a large increasing space for the indirect benefits of DG in the future.

DG cost-benefit model as described above mainly focus on the indirect benefits. Subsequent research could be carried out to take in-depth study on cost-benefit of DG under different conditions,such as hybrid power sources.

\section{Acknowledgment}

This work was supported by the National Natural Science Foundation of China(512770701) and the Fundamental Research Funds for the Central Universities(2014QN07). 


\section{References}

[1] I. F. Gull, "Small distributed generation versus centralized and supply:a social cost-benefit analysis in the residential service sectors:[J].Energy Policy, vol. 34, no. 7, (2006), pp. 804-832.

[2] G. C Bakos and N. F Tsagas, "Techno economic assessment of a hybrid solar/wind installation for electrical energy saving", [J].Energy and Buildings, vol. 35, no. 2, (2013), pp. 139-145

[3] R. J. Flores, B. P. Shaffer and J. Brouwer, "Economic and sensitivity analyses of dynamic distributed generation dispatch to reduce building energy cost", [J].Energy and Buildings, (2014), vol. 85, no. 12, pp. 293-304.

[4] M. H. Moradi and A. Khandani, "Evaluation economic and reliability issues for an autonomous independent network of distributed energy resources", [J].International Journal of Electrical Power \& Energy Systems, vol. 56, no. 5, (2014), pp. 75-82.

[5] M. B. Amor, P.-O. Pineau, C. Gaudreault and R. Samson, "Assessing the economic value of renewable distributed generation in the Northeastern American market", [J].Renewable and Sustainable Energy Reviews, vol. 16, no. 8, (2012), pp. 5687-5695.

[6] M. ZENG, K. TIAN and N. LI, "Economic Benefits Analysis of Distributed Generation and Its Assessment Model[J]. Power System Technology", [J], vol. 34, no. 8, (2010), pp. 129-133.

[7] D. Q. LI, J. Z. XU and S. YANG, "Benefits analysis of distributed generation and its quantitative models", [J]. Power System Protection and Control, vol. 40, no. 14, (2012), pp. 147-151.

[8] Y.Z. BAI, C.H. ZHANG and Z.X. GAO, "Economic assessment model of distributed generators"'J].energy engineering, vol. 33, no. 6, (2011), pp. 7-12.

[9] K. D. ZHU, X. Z. LI and Z.F. TAN, "Technology economy analysis model of energy saving and emission reduction technology in cold and hot gas distributed electrical systems", [J].Technology Economics, vol. 31, no. 5, (2012), pp. 82-86.

[10] J.Y. LEI, J. XIE and D.Q. GAN, "Energy optimization and benefit analysis of energy conservation and emissions reduction in distributed generation power system", [J].Automation of Electric Power System vol. 33, no. 23, (2009), pp. 29-36.

[11] Y. G. ZHONG, X. J. JIA and Y. QIAN Yin, "System dynamics", [M]. Beijing:Science Press, (second edition), (2013).

[12] L. LIU and S. TAO Shun,"Distributed generation and its impact on network loss of power system",[J]. Advanced Technology of Electrical Engineering and Energy, vol. 31, no. 3, (2012), pp. 16-19-24. 
International Journal of $u-$ and e- Service, Science and Technology Vol.9, No. 6 (2016) 